\title{
Curriculum System Evaluation of Intelligent Data Engineering Based on Electronic Information Engineering
}

\author{
Qingyu Zou ${ }^{1, a}$ and Dejun Liu, ${ }^{1, b^{*}}$ \\ ${ }^{1}$ College of Electrical and Information Engineering of Beihua University, Jilin, China \\ azouqingyu2002@126.com, bdejunliu@126.com \\ * The corresponding author
}

Keywords: Intelligent data engineering; Complex network; Curriculum system

\begin{abstract}
Intelligent data engineering is a multidisciplinary professional. It helps companies master the solution of various typical problems in large data applications from large data applications such as data management, system development, mass data analysis and mining. In this paper we analyzes the curriculum system of electronic information engineering and intelligent data engineering based on the theory of complex network. Firstly, we construct the complex network models of electronic information engineering and intelligent data engineering. And then we replace the main course, and analyze the topology structure of them. The results show that the network model can accurately evaluate the influence of curriculum changes on the professional curriculum system.
\end{abstract}

\section{Introduction}

Intelligent data engineering is the result of cross-disciplinary development. This specialty focuses on understanding the cognitive process, focusing on improving machine learning and pattern recognition algorithms. The development of this professional is conducive to expanding the application of intelligent science and promote the development of intelligent science. Intelligent data engineering includes statistical sampling, estimation and hypothesis testing, artificial intelligence, pattern recognition, machine learning algorithms, modeling techniques and learning theory content. Focusing on data storage, indexing and query processing technology, high performance computing technology and distributed data processing technology. Electronic information engineering is the backbone of the field of information science. It is a subject of electronic information control and information processing, mainly to study the information acquisition and processing, electronic equipment and information systems design, development, application and integration. Electronic information engineering major training with electronic technology, information processing technology and radio and television technology senior technical personnel, which has the technical and information processing technology and radio and television technology, has a certain ability to innovate and strong practical ability to be in the radio and television industry and other industries engaged in electronic information and related areas of the design, development, application and integration. Based on the theory of complex network, we constructed the network of curriculum of electronic information engineering according to the interrelationship between classes, and builds the curriculum network of intelligent data engineering based on this. And then we analyzed the topology structure of the network model of intelligent data engineering and electronic information engineering. The results accurate evaluation of the main courses of intelligent data engineering professional, including "Development and application of large data", "Development and Application of Cloud Platform", "Cloud computing and virtualization technology" and "Large data security".

\section{Construction of Curriculum Relationship Network}

We take the courses in the professional curriculum system as the nodes of the network and the relationship between the courses as the links of the network. Then we can express the curriculum system 
as a complex network model. We can understand the importance of each course in the course system by analyzing the topology of the network model[1,2].

Construction of Courses Relationship Network Model of Electronic Information Engineering. Electronic information engineering is specialized in computer technology, electronic information processing technology, communication technology and other modern electronic information technology integration. The main research content is information collection and processing, electronic and information system design, development, application and integration. The professional has a total of more than 70 courses, including circuit theory, information theory and coding, signal and system, digital signal processing, electromagnetic theory, automatic control principle. We chose 66 important courses as shown in Table 1 to build a curriculum relationship network.

We build a curriculum relationship network based on the interdisciplinary relationship of the curriculum. The network is a directed and weighted network. The nodes in the network are the courses in Table 1. The edge of the network is the relationship between the courses. The weight of a course is the size of a course that affects another course. For example, the Advanced Mathematics course is the basic course for signal and system courses. More than $50 \%$ of the signal and system course knowledge is related to higher mathematical knowledge. Thus, there is a slight difference between the higher mathematics and the two nodes of the signal and the system, with an edge weight of 0.5. Electronic information engineering courses network as shown in Figure 1. The network contains 66 nodes, 620 links, the average degree is 1.3338 , the average out-closeness is 5.7023 , the average in-closeness is 4.6657, global clustering coefficient is 0.793[3-6].

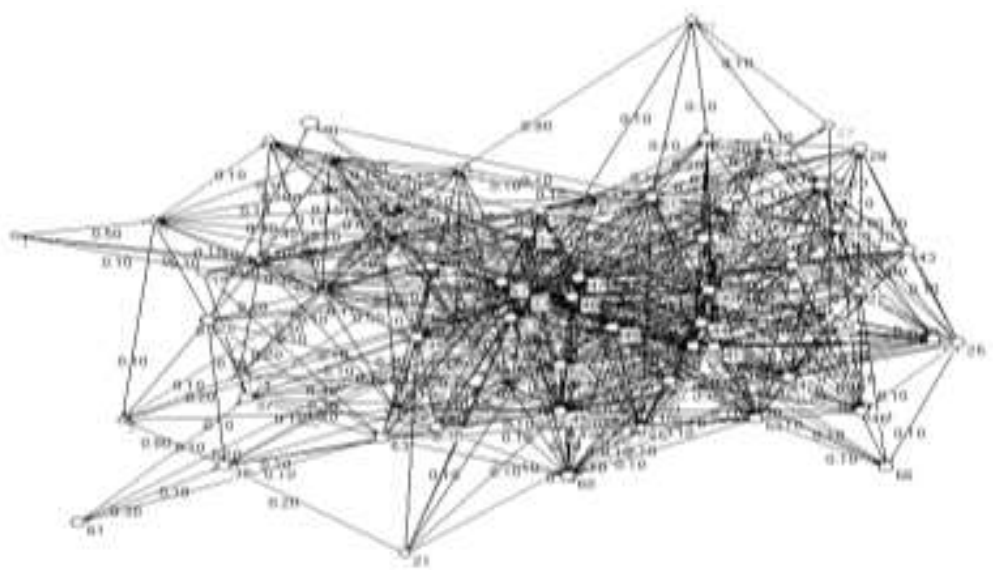

Figure 1. Courses Relationship Network Model of Electronic Information Engineering

Intelligent data engineering professional curriculum network. Intelligent data engineering increased "Development and application of large data", "Development and Application of Cloud Platform", "Cloud computing and virtualization technology" and "Large data security" curriculum based on electronic information engineering. The curriculum network as shown in Figure 2. The network contains 70 nodes, 662 links, the average degree is 2.6257 , the average out-closeness is 5.6323 , the average in-closeness is 4.7527 , the global clustering coefficient is 0.8069 .

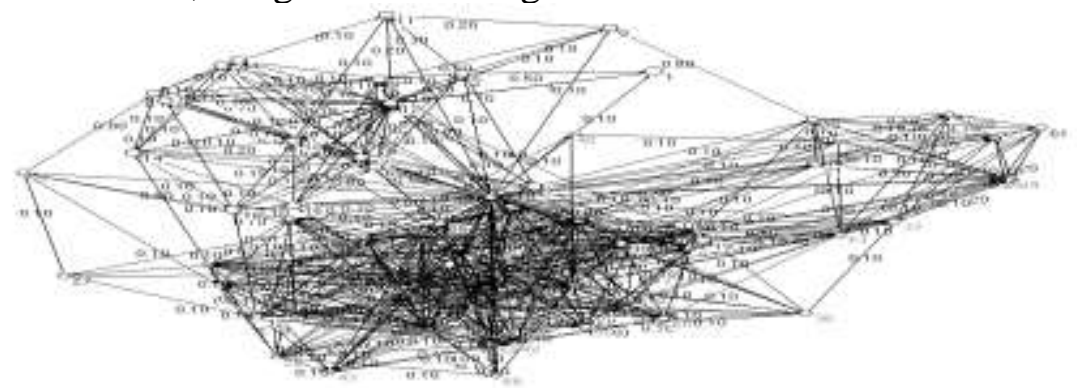

Figure 2. Courses Relationship Network Model of Intelligent Data Engineering 
Table 1 Courses of electronic information engineering

\begin{tabular}{|c|c|c|c|c|c|}
\hline No. & Course name & No. & Course name & No. & Course name \\
\hline 1 & $\begin{array}{l}\text { Basic manufacturing } \\
\text { technology practice }\end{array}$ & 23 & Linear Algebra & 45 & $\begin{array}{l}\text { Industrial field bus control } \\
\text { technology }\end{array}$ \\
\hline 2 & $\mathrm{VC}++$ practice & 24 & Probability and Statistics & 46 & $\begin{array}{l}\text { Knowledge extension of } \\
\text { signal and system theory }\end{array}$ \\
\hline 3 & $\begin{array}{l}\text { Electronic technology } \\
\text { practice }\end{array}$ & 25 & $\begin{array}{l}\text { Complex Analysis and } \\
\text { Integral Transformation }\end{array}$ & 47 & Electronic System Design \\
\hline 4 & EDA practice & 26 & Physics of college & 48 & $\begin{array}{l}\text { DSP Technology and } \\
\text { Application }\end{array}$ \\
\hline 5 & Production practice & 27 & Physics of college experiment & 49 & Image Processing Technique \\
\hline 6 & MCU interface practice & 28 & Analog Electronic Technique & 50 & Electromagnetic Field Theory \\
\hline 7 & $\begin{array}{l}\text { ARM information system } \\
\text { practice }\end{array}$ & 29 & Circuit Theory & 51 & Electronic Measurement \\
\hline 8 & DSP practice & 30 & Digital Electronic Technique & 52 & Television technique \\
\hline 9 & Image processing practice & 31 & $\begin{array}{c}\text { Analog Electronic Technique } \\
\text { experiment }\end{array}$ & 53 & $\begin{array}{c}\text { DSP Engineering Case } \\
\text { Analysis }\end{array}$ \\
\hline 10 & $\begin{array}{l}\text { Electronic system } \\
\text { engineering practice }\end{array}$ & 32 & $\begin{array}{c}\text { Digital Electronic Technique } \\
\text { experiment }\end{array}$ & 54 & $\begin{array}{l}\text { Technology of Information } \\
\text { and Coding }\end{array}$ \\
\hline 11 & Graduation practice & 33 & The Professional Introduction & 55 & $\begin{array}{c}\text { Digital Speech Processing } \\
\text { Technique } \\
\end{array}$ \\
\hline 12 & Graduation design & 34 & $\begin{array}{l}\text { Micro-Computer Principle } \\
\text { And Application }\end{array}$ & 56 & $\begin{array}{c}\text { Pattern Identification and } \\
\text { Application }\end{array}$ \\
\hline 13 & Circuit CAD practice & 35 & The Special English & 57 & Multimedia technique \\
\hline 14 & Electronic circuit practice & 36 & Sensors Technology & 58 & $\begin{array}{c}\text { Digital communication } \\
\text { system }\end{array}$ \\
\hline 15 & Digital electronic practice & 37 & Java Program Designing & 59 & $\begin{array}{c}\text { Optical Fiber Communication } \\
\text { Techniques }\end{array}$ \\
\hline 16 & Electronic CAD practice & 38 & VC++ Programing & 60 & $\begin{array}{l}\text { The New technology of } \\
\text { electronic information }\end{array}$ \\
\hline 17 & $\begin{array}{l}\text { DSP Comprehensive } \\
\text { Practice }\end{array}$ & 39 & $\begin{array}{l}\text { Single-chip Micro-computer } \\
\text { And Interface Technology }\end{array}$ & 61 & $\begin{array}{c}\text { Application Technology of } \\
\text { Database }\end{array}$ \\
\hline 18 & College Chinese & 40 & $\begin{array}{l}\text { Mechanical Drawing and } \\
\text { CAD }\end{array}$ & 62 & Microwave Technique \\
\hline 19 & College Foreign Language & 41 & Signal and System & 63 & Computer Networks \\
\hline 20 & $\begin{array}{c}\text { University Computer } \\
\text { Foundation }\end{array}$ & 42 & $\begin{array}{l}\text { The Principle of } \\
\text { Communication }\end{array}$ & 64 & $\begin{array}{l}\text { Embedded Systems and } \\
\text { Application }\end{array}$ \\
\hline 21 & $\begin{array}{l}\text { Computer programming } \\
\text { (C language) }\end{array}$ & 43 & $\begin{array}{c}\text { High frequency electronics } \\
\text { Technology }\end{array}$ & 65 & $\begin{array}{c}\text { EDA Technology and } \\
\text { Application }\end{array}$ \\
\hline 22 & Advanced Mathematics & 44 & Digital Signal Processing & 66 & Automatic Control Theory \\
\hline
\end{tabular}

\section{Curriculum Evaluation of Degree Distribution Based on Degree Distribution}

Degree is also called connectivity. It is one of the simplest and most important attributes of a network node $[7,8]$. The degree of the node is the number of all edges connected to it. In the directional network, the degree of the node is divided into in-degree and out-degree. In the network with adjacency matrix $A(n \times n)$, if there is an edge from node $i$ to node $j$, then $A_{i j}=1$, then the out-degree $k^{\text {out }}$ and in-degree $k^{\text {in }}$ of nodes are respectively.

$$
k_{i}^{\text {out }}=\sum_{j=1}^{n} A_{i j}, \quad k_{j}^{i n}=\sum_{i=1}^{n} A_{i j}
$$


The distribution of nodes in the network is one of the most important attributes. It can be described by the distribution function $P(k)$ and the cumulative distribution function $P_{c}(k) . P(k)$ represents the proportion of nodes with degrees $k$ in all nodes, and $P_{c}(k)$ represents the proportion of nodes with degrees greater than or equal to $k$ in all nodes. The degree and degree cumulative distribution of electronic information engineering as shown in Figure 3. The degree and degree cumulative distribution of intelligent hardware and product design as shown in Figure 4. We replace "DSP Engineering Case Analysis", "Digital communication system", "Single-chip Micro-computer and Interface Technology" and "Computer Networks" with intelligent "Development and application of large data", "Development and Application of Cloud Platform", "Cloud computing and virtualization technology" and "Large data security", respectively. The degree and degree cumulative distribution of intelligent hardware and product design as shown in Figure 5. As can be seen from the figure, the original curriculum on the curriculum system is very small.
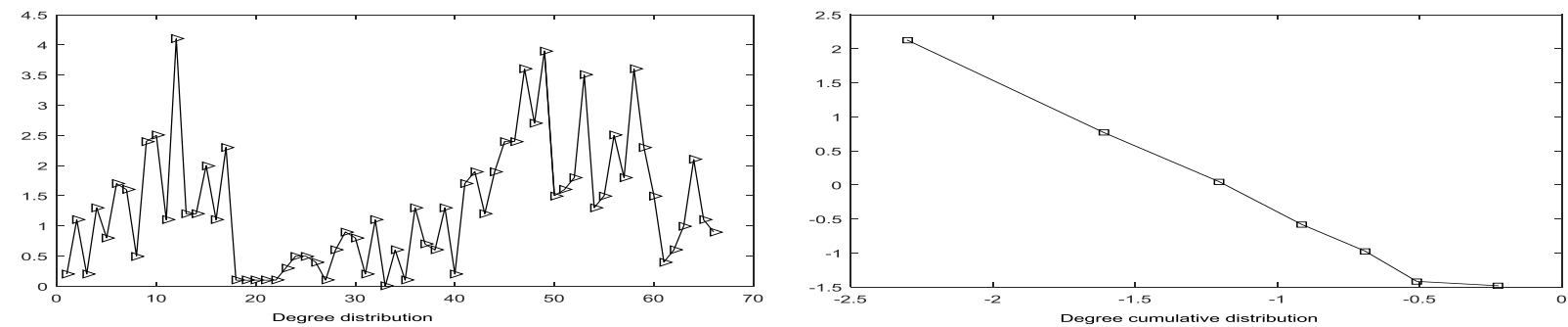

Figure 3. Degree and cumulative degree distribution of electronic information engineering
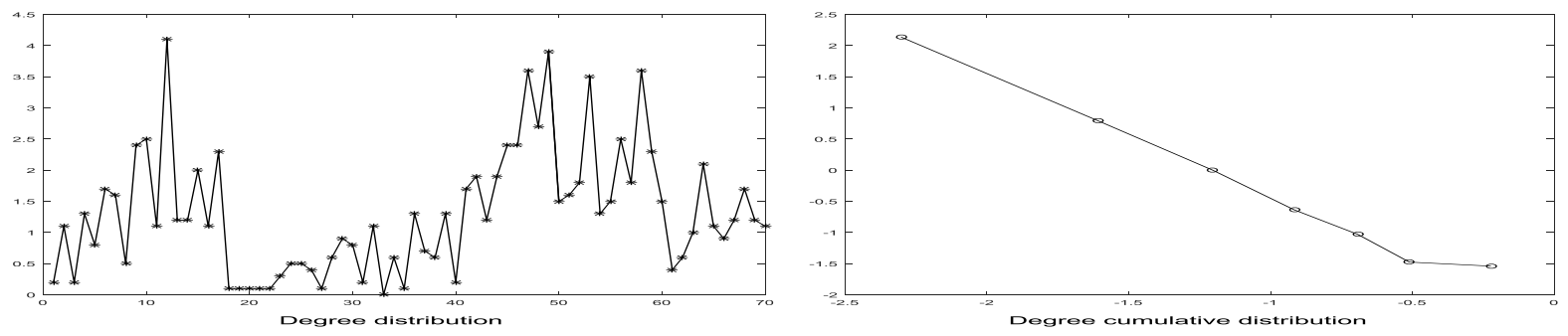

Figure 4. Degree and cumulative degree distribution of intelligent data engineering
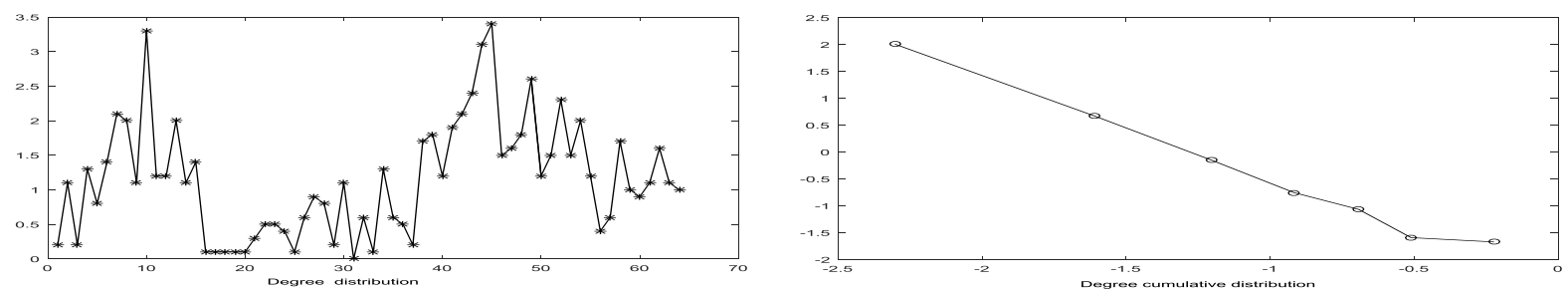

Figure 5. Degree and cumulative degree distribution of intelligent data engineering after the replacement of courses

\section{Summary}

Intelligent data engineering is the inevitable product of social development. In this paper we analyzes the curriculum system of electronic information engineering and intelligent data engineering based on the theory of complex network. Firstly, the network models of electronic information engineering and intelligent data engineering are constructed. And then we analyzed the topology of the network models of electronic information engineering and intelligent data engineering. The results show that the model can accurately evaluate the influence of curriculum changes on the professional curriculum system. 


\section{Acknowledgement}

This work is supported partially by the Key Education Research Project of Beihua university (Grant NO. XJZD2016039), partially by the Jilin Province Science and Technology Development Project(Grant NO. 20170520057JH), partially by the Beihua University Dr. Scientific Research Fund (Grant NO. 199500103), partially by the university-enterprise cooperation comprehensive reform project of intelligent information processing and networking professionals (Grant NO. SJXQ005).

\section{References}

[1] E. Schoell, "Complex Dynamical Networks," in Controlling Synchronization Patterns in Complex Networks(Springer Theses-Recognizing Outstanding PhD Research, 2016, pp. 15-29.

[2] F. A. Rodrigues, T. K. D. M. Peron, P. Ji, and J. Kurths, "The Kuramoto model in complex networks", Physics Reports-Review Section of Physics Letters, vol. 610, pp. 1-98, Jan 262016.

[3] M. S. Baptista, "Complex Networks," in Energy Transmission and Synchronization in Complex Networks: Mathematical Principles(Springer Theses-Recognizing Outstanding PhD Research, 2016, pp. 13-43.

[4] P. Hu, W. Fan, and S. Mei, "Identifying node importance in complex networks", Physica a-Statistical Mechanics and Its Applications, vol. 429, pp. 169-176, Jul 12015.

[5] K. Erciyes and K. Erciyes, Analysis of Complex Networks (Complex Networks: An Algorithmic Perspective). 2015, pp. 63-78.

[6] T. Huang, Z. Yang, and C. Li, "Theory and Applications of Complex Networks", Mathematical Problems in Engineering, 2014 2014, Art. no. 315059.

[7] M. Egerstedt, "COMPLEX NETWORKS Degrees of control", Nature, vol. 473, pp. 158-159, May 2011.

[8] G. Ghoshal and M. E. J. Newman, "Growing distributed networks with arbitrary degree distributions", European Physical Journal B, vol. 58, pp. 175-184, Jul 2007. 